\title{
Impact of a psychiatric day hospital programme on psychoparmacological treatment
}

\author{
Sónia Farinha-Silva ${ }^{1}$, Inês Donas-Boto², Maria Fátima Urzal², Paula Duarte² \\ ${ }^{1}$ Unidade Local de Saúde do Baixo Alentejo, Psychiatry, Beja, Portugal \\ ${ }^{2}$ Centro Hospitalar Lisboa Ocidental, Psychiatry and Mental Health Department, Lisbon, Portugal
}

Our Psychiatric Day Hospital (PDH) accommodates a 5 day-aweek program for psychiatric patients aged 18 to 65 years old, without organic or substance-abuse disorders. It consists on psychodynamic group therapy as its central feature and also individual psychotherapy, psychiatric consultations, family interventions and other therapeutic and occupational activities with a planned treatment period of one year. The authors present and analyze the effect of the PDH programme on the TD of psychopharmaceuticals prescribed.

\section{Objectives}

To determine the impact of a PDH programme on the total dosage (TD) of psychotropic drugs prescribed per patient upon program completion.

\section{Materials and Methods}

Study population included all patients that completed the PDH treatment programme between May 2013 and January 2019. All patient information was extracted from the patients' medical records. Collected data included age, gender, diagnosis and dosages of antidepressants, benzodiazepines and antipsychotics at admission and at discharge.

\section{Results}

\begin{tabular}{|c|c|c|c|c|}
\hline & $\begin{array}{c}\text { Affective } \\
\text { disorders }\end{array}$ & $\begin{array}{c}\text { Personality } \\
\text { disorders }\end{array}$ & $\begin{array}{c}\text { Psychotic } \\
\text { disorders }\end{array}$ & $p$-value \\
\hline $\mathrm{n}$ total & 15 & 9 & 17 & \\
\hline Male $(\mathrm{n}, \%)$ & $8(53 \%)$ & $4(44 \%)$ & $6(35 \%)$ & 0.62 \\
\hline Female (n, \%) & $7(47 \%)$ & $5(56 \%)$ & $11(65 \%)$ & \\
\hline $\begin{array}{c}\text { Mean Age } \\
\text { (min., máx.) }\end{array}$ & $37(30,41)$ & $27(20,30)$ & $36(31,39)$ & 0.093 \\
\hline $\begin{array}{c}\text { Mean time in } \\
\text { month } \\
\text { (min. máx.) }\end{array}$ & $12(5,16)$ & $9(7,12)$ & $17(13,21)$ & 0.019 \\
\hline
\end{tabular}

Multivariate analysis showed a significant decrease in the dosage of benzodiazepines and antipsychotics. In antidepressants this decrease was not significant.

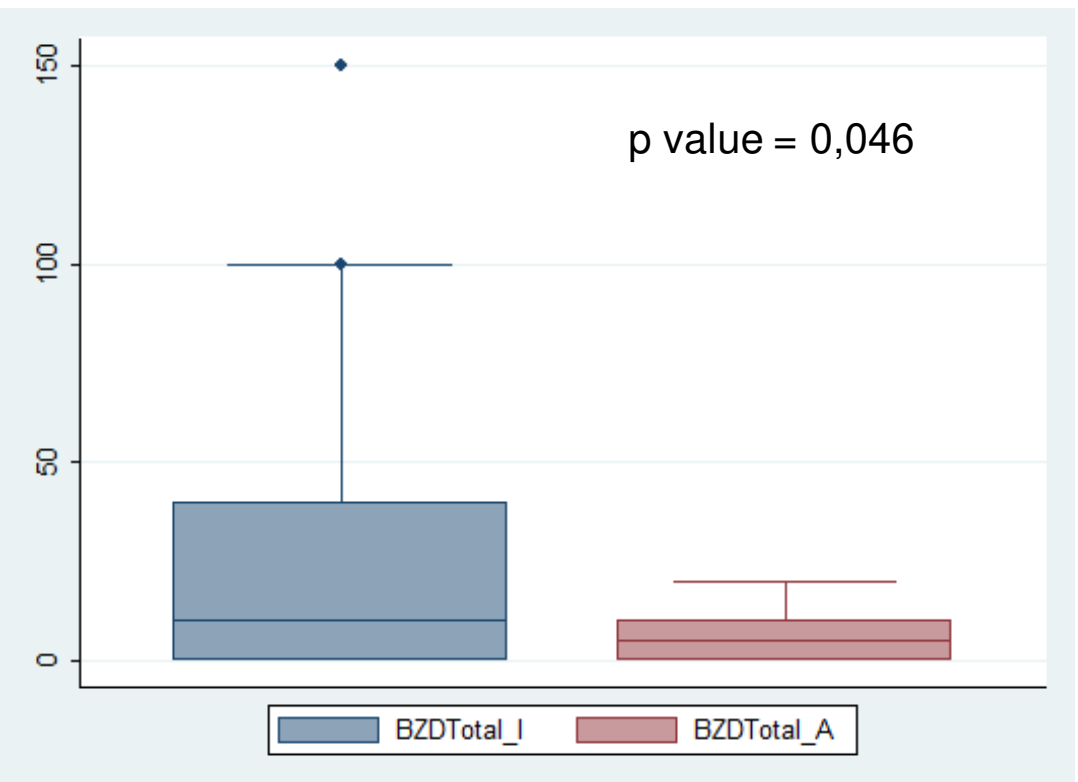

Graph 1 - In blue the total dose of benzodiazepines at admission and in red the total dose at discharge

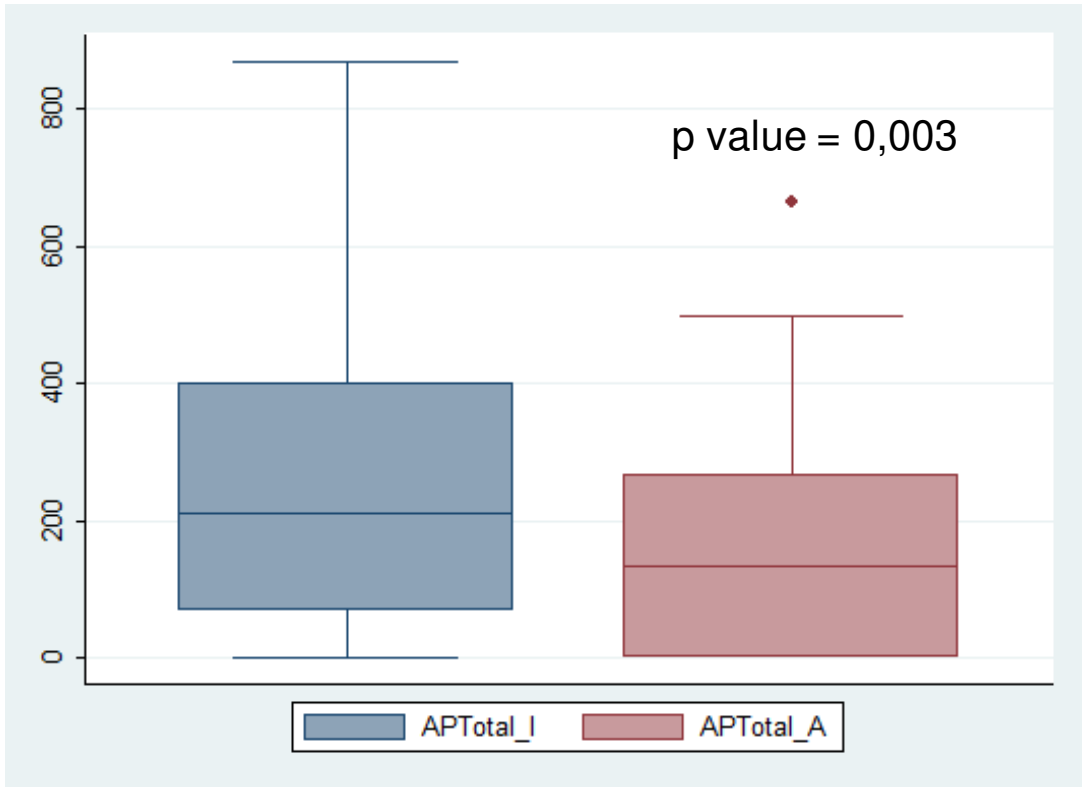

Graph 2 - In blue the total dose of antipsychotics at admission and in red the total dose at discharge

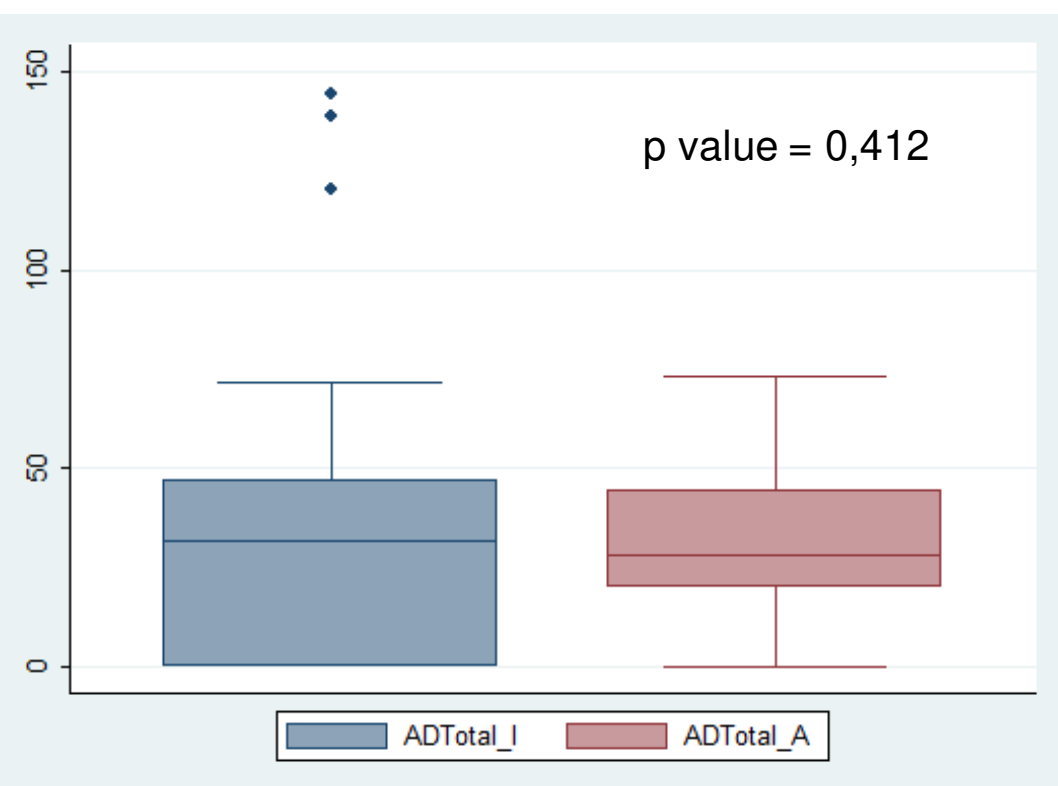

Graph 3 - In blue the total dose of antidepressants at admission and in red the total dose at discharge

\section{Conclusions}

Our PDH psychotherapeutic program combined with standard drug care seems to be successful regarding the decrease of the TD. Several factors may contribute, including the completion of a psychotherapeutic programme and the greater flexibility of pharmacological adjustment provided by the daily contact with patients.

\section{Sources}

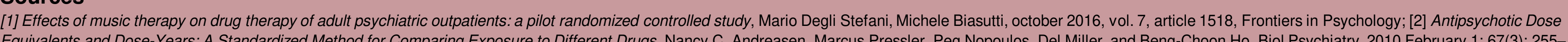

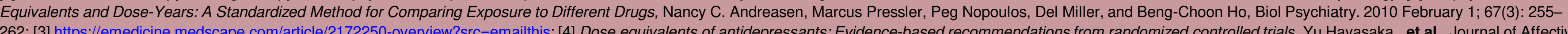

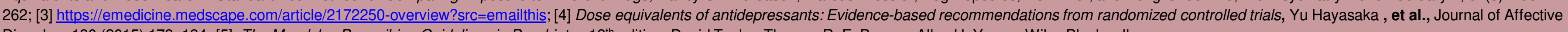
Disorders 180 (2015) 179-184; [5] The Maudsley Prescribing Guidelines in Psychiatry, $13^{\text {th }}$ edition, David Taylor, Thomas R. E. Barnes, Allan H. Young, Wiley Blackwell 